\title{
(Re)visitando Gramsci: considerações sobre o Estado e o poder
}

\author{
Kathleen Elane Leal Vasconcelos \\ Universidade Estadual da Paraíba (UEPB)
}

\section{Mauricelia Cordeira da Silva}

Faculdade Leão Sampaio, Juazeiro do Norte, Ceará

\author{
Valdilene Pereira Viana Schmaller \\ Universidade Federal de Pernambuco (UFPE)
}

\section{(Re)visitando Gramsci: considerações sobre o Estado e o poder}

Resumo: O objetivo deste artigo é revisitar as contribuições gramscianas sobre a sociedade capitalista, com ênfase em suas reflexões sobre o Estado e o poder. Situa, inicialmente, os elementos sócio-históricos fundantes da análise do autor, inscritos no cenário particular da transição do capitalismo concorrencial ao estágio monopolista do capital. Resgata as bases teórico-analíticas do pensamento de Gramsci, a partir da singular contribuição dos escritos de Marx e Engels para formulação da noção de Estado ampliado. Defende a atualidade do pensamento de Gramsci para o desvelamento do ethos capitalista, principalmente para análise das estratégias contemporâneas de recomposição da hegemonia burguesa.

Palavras-chave: Estado. Poder. Gramsci. Hegemonia.

\section{(Re)visiting Gramsci: considerations about the State and power}

Abstract: The purpose of this article is to revise the Gramscian contributions about capitalist society, with an emphasis on his reflections about the State and power. It first situates the foundational socio-historic elements of the author's analysis, inscribed in the particular scenario of the transition from competitive capitalism to the state of monopoly capitalism. It revives the theoreticalanalytical bases of Gramsci's thinking, based on the unique contributions of the writings of Marx and Engels to the formulation of the concept of the expanded State. It defends the current relevance of Gramsci's thinking to the revelation of the capitalist ethos, principally by the analysis of the contemporary strategies of recomposition of the bourgeois hegemony.

Keywords: State. Power. Gramsci. Hegemony. 


\section{Algumas palavras iniciais}

No debate hodierno acerca da política, a referência ao pensamento de Antônio Gramsci é fundamental em virtude de sua teoria acerca do Estado. É o pensador marxista, posterior à época clássica, mais respeitado no Ocidente (ANDERSON, 1981) ${ }^{1}$. Concomitantemente, poucas obras são passíveis de colossais distinções de interpretações quanto a dele, especialmente os Cadernos do cárcere ${ }^{2}$. Estes são invocados como referência por analistas das mais distintas correntes teóricas e posições políticas, o que leva a uma admiração tão diversificada que, segundo Anderson (1981), só pode originar ambiguidades e traduções até mesmo incompatíveis; ou conduzir ao uso instrumental do autor para legitimar ideias políticas opostas, conforme alertam Acanda (2006) e Dias (1996a).

Não obstante, é inegável a contribuição gramsciana para uma análise densa e crítica da sociedade e do Estado moderno (bem como para iluminar as reflexões sobre a revolução comunista), tarefa que, para ser realizada sem distorções, não deve isolar as categorias e os conceitos gramscianos da totalidade de seu pensamento.

Nesta direção, aqui não se toma Gramsci como o analista da "política", mas se considera sua perspectiva de indissociabilidade entre as esferas constitutivas da realidade social, explicitando particularmente as relações que apreende entre a política e a economia. O objetivo desse artigo é (re)visitar as contribuições gramscianas sobre a sociedade capitalista, com ênfase em suas reflexões sobre o Estado e o poder ${ }^{3}$.

\section{Situando o pensamento gramsciano}

Como militante e teórico, as questões que inquietavam Gramsci estavam profundamente relacionadas com o contexto em que viveu, marcado pela primeira grande crise civilizatória do capitalismo e sua transição da fase concorrencial ao período monopólico ou imperialista (ACANDA, 2010), com todas as suas implicações.

Em tal contexto, evidenciando a saturação do modelo liberal, o próprio Estado redefinia-se, assumindo funções cada vez mais determinantes na economia. Os movimentos organizativos das classes subalternas eclodiam em diversas partes da Europa, com suas reivindicações por melhores condições de trabalho e de vida, insinuando, pela primeira vez, uma ameaça global ao poder da burguesia (ACANDA, 2010). A intervenção do Estado em relação a tais questões começava a ultrapassar a dimensão repressiva e traduzia-se em novas medidas, como a execução (ainda que incipiente) de políticas sociais.

Nesta arena, apesar da vitória da Revolução de Outubro e da ebulição dos partidos comunistas em todo o continente europeu, o movimento operário não foi vitorioso em nenhum país da Europa. O que ocorreu foi uma recomposição do poder burguês, demonstrada em todo vigor via fascismo e nazismo (ACANDA, 2006).

Como militante do partido comunista e preso político do regime autocrático italiano, a grande questão que tocava Gramsci era: "por que perdemos?” (GRUPPI, 1980; ACANDA, 2006). Foi esta linha analítica que atravessou suas elucubrações no cárcere, tendo como norte a necessidade de redimensionamento da luta revolucionária.

Para responder tal indagação, Gramsci deu-se conta de que não bastava a crise econômica e a organização operária para que o capitalismo fosse suplantado: o poder parecia não se circunscrever apenas ao campo econômico ou à "tomada do Estado". Gramsci mergulhou em profundas reflexões, traçando, de forma pioneira, um "sistema conceitual completo para apreender de forma unitária a complexa fenomenologia do poder nas sociedades capitalistas contemporâneas" (ACANDA, 2010, p. 172). Ele se voltou para um ângulo pouco explorado pelo marxismo de sua época: o Estado e a política.

Nessa tarefa, enfrentou dois vultosos adversários: o liberalismo e o marxismo economicista (ACANDA, 2006). Ao primeiro, contrapôs o ponto de vista classista do Estado burguês; ao segundo, propôs o resgate da abordagem marxista dialética da realidade, enriquecendo e ampliando as reflexões sobre a política, como se verá a seguir.

\section{Bases da reflexão de Gramsci: a angulação marxiana}

Para Gramsci, a política e o Estado não podiam ser pensados abstratamente ou como esferas isoladas, como propõem as ciências sociais particulares, nascentes no período em que Gramsci realizava suas reflexões, mas tratados sob o princípio da totalidade, numa análise embasada na crítica da economia política empreendida por Marx.

Acanda (2010), Coutinho (1996) e Simionatto (2004) declaram enfaticamente que, distante de ser um "politólogo", o pensador sardo não inverteu nem negou as descobertas essenciais de Marx. Na verdade, segundo Acanda (2010), ele teve como ponto de partida a aceitação dos princípios basilares do materialismo histórico e dialético. Nas palavras de Coutinho (1981, p. 88), Gramsci considera "que a produção e a reprodu- 
ção da vida material, implicando a produção e a reprodução das relações sociais globais, é o fator ontologicamente primário na explicação da história”.

Cumpre registrar, ainda, que de forma sumária, alguns traços das reflexões marxianas sobre a questão estatal ${ }^{4}$. Ao criticar a concepção hegeliana do Estado como encarnação da Razão Universal, Marx (1979, p. 82) considera que tanto o Estado quanto as relações jurídicas "não podem ser explicados por si mesmo, nem pela chamada evolução geral do espírito humano: estas relações têm, ao contrário, suas raízes nas condições materiais de existência", ou seja, têm gênese nas relações sociais concretas.

Ele constata que o Estado coloca-se como representante do interesse comum e se atribui a responsabilidade de assegurar a igualdade política, eliminando as distinções sociais que caracterizavam a sociedade feudal, estabelecidas por nascimento, posição social, educação e profissão (MARX, 2005). Contudo, ao mesmo tempo, permite que tais elementos atuem a seu modo, de forma que, "bem longe de acabar com essas diferenças de fato, o Estado só existe sobre essas premissas, só se sente como 'Estado político' e só faz valer a sua 'generalidade' em oposição a tais elementos" (MARX, 2005, p. 21). Dessa forma, o indivíduo vive uma cisão: na sociedade política ele é considerado um ser comunitário, um cidadão, enquanto que na sociedade civil age como indivíduo privado, sujeito aos interesses egoístas da lógica capitalista. Embora juridicamente os direitos políticos estejam assegurados, eles não modi-

ficam as condições que geram as distinções sociais entre os homens. Assim, o Estado garante a propriedade privada, assegurando a reprodução da divisão da sociedade em classes (COUTINHO, 1996).

Ao fazer tal constatação, Marx, em texto escrito junto com Engels, afirma que "o executivo do Estado moderno não é mais do que um comitê para administrar os negócios coletivos de toda a classe burguesa" (MARX; ENGELS, 1998, p. 7). Além disso, em outro texto, menciona que o Estado tem a função de "manutenção da ordem social" (MARX, 1999, p. 15). Na análise de Coutinho (1996), Marx considerava o Estado como um Estado de classe que, em nome de um suposto interesse geral, defende os interesses comuns de uma classe particular.

Ao perceber que a natureza do Estado capitalista fora modificada pelos fenômenos econômicos e políticos que marcaram o panorama mundial a partir do início do século 20, como se traçou anteriormente, Gramsci amplia a análise marxista acerca do Estado. O pensador italiano observou que, de um lado, embora o Estado prosseguisse com seu caráter classista, não era mais apenas o comitê de negócios da burguesia: algumas demandas das classes subalternas foram por ele incorporadas. De outro lado, Gramsci constata que o monopólio da violência e a coerção não eram mais suficientes para a manutenção da ordem social: fazia-se necessário organizar novas formas de estabelecer o consenso, tarefa que passou a ser empreendida pelo Estado, através da formulação e disseminação de um conjunto de valores e normas políticas, sociais e culturais.

Em sua análise, Gramsci não realizou uma cisão entre as esferas constitutivas da sociedade, já que não haveria primeiro uma estrutura e depois uma superestrutura, mas um vínculo orgânico e dialético entre elas, correspondente a uma organização social concreta, como indica Portelli (2002). Assim, distintamente do marxismo vulgar, Gramsci possuía uma visão sistêmico-relacional da sociedade (ACANDA, 2010), conforme se delineará no item seguinte.

\section{Estado, economia e poder em Gramsci: a indissociabilidade entre as esferas constitutivas da realidade}

O entendimento de que a análise somente da esfera econômica (como propunha o marxismo vulgar) seria suficiente ao estudo dos processos em curso no cenário europeu foi fortemente criticada por Gramsci. Isto porque a concepção adotada pelo analista italiano, segundo Acanda (2010), pressupõe a compreensão do ser social - historicamente determinado - e da sociedade como um sistema de relações sociais que os homens estabelecem entre si no processo de produção e reprodução da vida social (ACANDA, 2007). Produção é concomitantemente reprodução, tanto da vida material e do modo de produção, quanto das formas de consciência e modo de vida na sociedade (IAMAMOTO; CARVALHO, 1985).

É nessa perspectiva de indissociabilidade das esferas constitutivas da realidade social que Gramsci (1968, p. 12) teceu o que viria a constituir a chave de análise central de seus estudos: o conceito de bloco histórico, apreendido enquanto uma "unidade entre a natureza e o espírito, entre vida e política (estrutura e superestrutura), unidade dos contrários e dos distintos" e a percepção do vínculo existente entre os elementos fundamentais do bloco histórico (estrutura e superestrutura). Para Gramsci, não existe uma relação de prima- 
zia de uma esfera sobre a outra, tampouco uma relação unilateral entre elas e, menos ainda, uma simples relação de causa e efeito, mas um vínculo orgânico e dialético, cujas determinações só podem ser apreendidas no conjunto das relações desenvolvidas em determinado processo histórico.

Nesta perspectiva, Coutinho mostra que Gramsci rejeita a redução da economia, ou seja, da estrutura, às relações técnicas de produção, ou às forças produtivas. Na apreensão gramsciana, a estrutura não diz respeito apenas à mera esfera da produção de objetos materiais, porém abrange a maneira como homens e mulheres “estabelecem seu 'metabolismo' com a natureza e produzem e reproduzem não só esses objetos materiais, mas, sobretudo, suas próprias relações sociais globais" (COUTINHO, 2011, p. 116). A estrutura, portanto, abarcaria não somente as forças produtivas, mas as relações sociais de produção, ou seja, o conjunto das relações sociais, a totalidade da vida social (COUTINHO, 2011). Argumenta ainda que Gramsci percebia que a totalidade não se limita à ação recíproca de seus vários momentos, porém possui um momento predominante: “a estrutura e as superestruturas formam um 'bloco histórico', ou seja, o conjunto complexo e contraditório das superestruturas é o reflexo do conjunto das relações sociais de produção" (GRAMSCI apud COUTINHO, 2011, p. 116). No entanto, isso não significa que a superestrutura constitua um simples epifenômeno, "mas [sim] algo que tem densidade ontológico-social".

Segundo Coutinho (2011, p. 120), para Gramsci - distintamente do marxismo economicista -, a maneira como a estrutura e a superestrutura ${ }^{5}$ se articulam não é dada a priori nem definitivamente: a forma de relação entre elas, assim como o papel do "momento predominante" que uma tem sobre a outra no interior da totalidade do ser social estão associados às configurações concretas de cada formação social. Na perspectiva gramsciana,

[...] o momento 'catártico', o momento da liberdade, da teleologia, do dever ser, da iniciativa dos sujeitos, ou, em suma, o momento da política, não é criação absoluta, não opera no vazio, mas no interior das determinações econômico-objetivas que limitam (mas sem de modo algum cancelar) as margens de realização da liberdade. Tal como nos clássicos do materialismo histórico, também em Gramsci a economia determina a política não através da imposição mecânica de resultados unívocos, 'fatais', mas antes [sic] delimitando o âmbito das alternativas que se colocam, em cada oportunidade concreta, à ação dos sujeitos (COUTINHO, 2011, p. 117-118).

A superestrutura seria, para Gramsci, compreendida como um conjunto dinâmico, complexo, e pleno de contradições, através do qual a classe hegemônica exerce sua dominação - via instrumentos repressivos ou culturais -, cuja função seria justamente disseminar a ideologia dominante para as classes subalternas e auxiliares, processo no qual o Estado, ao ampliar suas funções, sobretudo as de caráter educativo, teria papel fundamental (ACANDA, 2006).

Para o marxista italiano, o "cimento" do bloco histórico é a hegemonia, cuja concepção supera o entendimento da hegemonia enquanto mera aliança de classes (conforme pensara Lênin), ou como simples subordinação de uma classe em relação à outra: hegemonia seria a capacidade de direção política e cultural, ou seja, a de construir uma visão de mundo a ser incorporada pelas demais classes, como lembra Simionatto (1998).

Segundo Acanda (2007, p. 168), "el carácter hegemónico de una clase se expresa en su "capacidad para estructurar el sistema objetivo de relaciones sociales en formas afines a su poder, a sus intereses y a su reproducción como clase'." Desta forma, a hegemonia não é simplesmente uma "ideologia" eficaz, algo que está localizado meramente no campo da superestrutura, mas envolve aspectos ideológicos, culturais, políticos e econômicos. Em síntese, a hegemonia diz respeito à habilidade da classe dominante de

Obter e manter seu poder sobre a sociedade pelo controle que mantém sobre os meios de produção econômicos e sobre os instrumentos de repressão, mas, principalmente, por sua capacidade de produzir e organizar o consenso e a direção política, intelectual e moral dessa sociedade. A hegemonia é, ao mesmo tempo, direção ideológico-política da sociedade civil e combinação de força e consenso para obter o controle social (ACANDA, 2006, p. 178).

No processo de obtenção da hegemonia, vale assinalar a importância atribuída por Gramsci aos intelectuais orgânicos. Superando a concepção vulgar de sua época, através da qual os intelectuais eram vistos como um grupo autônomo e independente, ele observa que, enquanto criação das classes fundamentais, tais sujeitos assumem funções essenciais à manutenção da direção hegemônica de um bloco histórico.

Cada grupo social que nasce no terreno original de uma função social no mundo da produção econômica, cria, ao mesmo tempo em que a si mesmo, organicamente, uma ou várias camadas de intelectuais que lhe 
conferem homogeneidade e a consciência de sua própria função, não somente no plano econômico, mas também no plano político e social (GRAMSCI, 1966 apud PORTELLI 2002, p. 108).

Funcionários tanto da "sociedade civil", quanto "da sociedade política", estes intelectuais atuam, predominantemente, como agentes das classes dominantes, sendo responsáveis pela elaboração de um arcabouço ideológico, transformado em "concepção de mundo", capaz de impregnar todo o "corpo social" em favor das mesmas.

Neste processo de construção da hegemonia, portanto, a cultura é percebida como uma dimensão essencial da política ${ }^{6}$, e esta passa a ser apreendida em sua tarefa de estruturação da hegemonia de uma classe. A hegemonia não pode ser entendida apenas na esfera cultural ou política, mas no processo social como um todo: embora nasça da fábrica (GRAMSCI, 2008), ela se estende ao conjunto das relações sociais. Em seu estudo sobre o americanismo e o fordismo, constatou que as modificações apregoadas por Ford em relação aos novos métodos de trabalho e de produção não se limitavam ao interior das fábricas, mas visavam à criação de um novo senso psicofísico ${ }^{7}$ nos operários. Assim, a adaptação aos nascentes métodos laborais não se circunscrevia ao solo fabril, mas tinha seus tentáculos fortemente encravados no cotidiano dos operários, incluindo a vida familiar, o lazer, a sexualidade, a cultura etc., gerando modificações nas condições sociais, nos costumes, nos hábitos individuais.

Isso significa que as alterações no campo do modelo produtivo constituem-se como "indissolúveis de um determinado modo de viver, de pensar e de sentir a vida. Não é possível obter sucesso num campo sem obter resultados tangíveis no outro" (GRAMSCI, 2008, p. 69). Era necessário um novo modo de vida que, segundo Braga (2008, p. 16), tracejava-se como um “'modo de regulação ou mesmo de modelo de desenvolvimento' que, partindo do chão da fábrica, açambarca as dimensões mais íntimas da condição operária."

A hegemonia não é um fenômeno puramente psicológico ou moral, mas possui também um valor gnosiológico (SIMIONATTO, 2004), na medida em que a "apropriação" do mundo (ACANDA, 2006), por parte das classes subalternas, é contaminada pelo fetichismo ${ }^{8}$ e pela alienação. Além disso, a grande massa dos homens e das mulheres pensa de acordo com uma concepção de mundo que lhe é imposta mecanicamente e acatada de forma passiva9 (GRAMSCI, 2008).

A hegemonia implica a "transformação da objetividade burguesa em subjetividade"10 (SIMIONATTO, 1998, p. 57). Isso ocorre em um "movimento molecular" que atravessa as diversas relações sociais, passando pelos âmbitos familiar, escolar, artístico, moral, religioso etc. Neste sentido, "o poder se produz e se reproduz nos interstícios da vida cotidiana. É, por conseguinte, ubíquo e está presente em qualquer produto e relações sociais" (ACANDA, 2006, p. 205).

A partir desta perspectiva de indissociabilidade dos elementos constitutivos do bloco histórico e do papel da hegemonia nesse processo, pode-se afirmar que, em Gramsci (2008), o capitalismo não significa apenas produção de mercadorias, mas "produção" de indivíduos, de aparatos jurídicos e de aparelhos privados de hegemonia difusores da ideologia dominante. Sob esta ótica, como releva Acanda (2010), o capitalismo é, acima de tudo, um modo de produção de relações sociais, posto que o poder burguês tem suas bases em um determinado tipo de padrão civilizatório (que de modo algum se limita à produção econômica), de cultura, de modo de vida dos indivíduos.

A teoria gramsciana sobre hegemonia contribui para entender a especificidade do Estado na sociedade capitalista contemporânea, conforme se abordará a seguir.

\section{Estado: papel econômico e civilizatório}

De forma distinta de Marx, para quem a sociedade civil referia-se às relações econômicas e a sociedade política ao aparelho estatal, Gramsci (1968, p. 149) ampliou a noção de Estado, ao defender que nela "entram elementos que também são comuns à noção de sociedade civil (neste sentido, poder-se-ia dizer que Estado = sociedade política + sociedade civil, ou seja, hegemonia revestida de coerção)". A sociedade política ${ }^{11}$ seria composta pelo conjunto de mecanismos através dos quais a classe dominante detém o monopólio legal da repressão e da violência (GRAMSCI, 1968, p. 149).

Como afirma Gruppi (1980), na concepção gramsciana, a sociedade política é uma extensão da sociedade civil, abarca um campo extremamente largo, já que se delineia como o terreno da ideologia. É no campo da sociedade civil que são disseminados os valores e interesses da classe dirigente, entrelaçando-se "o consenso e a direção moral e intelectual do conjunto social. Nela se forma a vontade coletiva, se articula a estrutura material da cultura e se organiza o consentimento e a adesão das classes dominadas" (GRUPPI, 1980, p. 175). Desta maneira, a sociedade civil envolve as multifacetadas organizações responsáveis pela elaboração e/ou difusão de ideologias, abrangendo escolas, igrejas, partidos políticos, sindicatos, organizações profisssionais, meios de comunicação etc. (COUTINHO, 2005). 
Para Acanda (2006), até mesmo as organizações econômicas podem ser incluídas na sociedade civil. Embora inserido na estrutura econômica, o mercado está também situado na esfera da sociedade civil, posto que não significa simplesmente compra e venda, mas uma forma de espraiamento da lógica do fetichismo. $\mathrm{O}$ mercado capitalista exerce igualmente um papel fundamental na socialização dos indivíduos, mas

[...] é, em consequência, uma agência de 'civismo', de produção, difusão e reafirmação de normas e valores e dos códigos simbólicos específicos que dão significado concreto ao sentido da sociabilidade, da solidariedade e da comunidade (ACANDA, 2006, p. 191).

A concepção ampliada sobre sociedade civil contribuiu para que Gramsci identificasse o papel determinante que o Estado exerce na construção do sistema hegemônico, papel este expresso na dupla e concomitante função: assegurar as condições necessárias à expansão econômica e "educar" para alcançar o consenso.

Em relação à primeira função, o Estado é na verdade a empresa "que concentra as economias a serem postas à disposição da indústria e da atividade privada, como investidor a médio e longo prazo" (GRAMSCI, 1968, p. 84), tornado o maior organismo plutocrático, em suas íntimas relações com o grande capital financeiro. No entanto, ainda que seu papel constitua-se indispensável às classes que estão no poder, o teórico italiano observou que a direção hegemônica das referidas classes exige do Estado a intervenção na formação e disseminação de novos códigos ideológicos e novos padrões de condutas, um Estado "educador" do consenso.

É neste sentido que a função pedagógica do Estado tem um papel preponderante no estabelecimento de um sistema hegemônico: criar e manter determinado padrão cultural, visando "adequar a "civilização' e a moralidade das mais amplas massas populares às necessidades do desenvolvimento continuado do aparelho econômico de produção, portanto elaborar também fisicamente novos tipos de humanidade" (GRAMSCI, 1968, p. 91). O Estado, com suas múltiplas organizações na sociedade civil, tornou-se, assim, um "educador", um canal de produção, difusão e afirmação de determinado modo de vida. Sobre o tema, Acanda (2006, p. 176) assinala que é indispensável que a classe dirigente exerça o poder, assuma o domínio da produção, difusão e aceitação de valores e normas de comportamento. Tal poder apoia-se, principalmente, "no controle das instituições que conferem sentido: aquelas que definem e justificam o indivíduo, ensinam-no a pensar de certa maneira e não de outra, indicam-lhe os valores que deve compartilhar, as aspirações permitidas e as fobias imprescindíveis."

Apesar da importância do consenso, bem como da busca de "equilíbrio" entre coerção e consenso, nas situações de crise, ameaça ou perigo ao sistema, lança-se mão da repressão, como lembra Anderson (1981, p. 33),

[...] el poder capitalista puede considerarse, e nese sentido, como un sistema topológico con un centro 'móvil': en cualquier crisis se produce un redespliegue y el capital va a concentrarse de sus aparatos representativos a los represivos.

Este tipo de concepção sobre o Estado e sobre o capitalismo coloca novas tarefas para o movimento revolucionário, como se comentará brevemente a seguir.

\section{Classes subalternas e a tarefa revolucionária}

Uma preocupação recorrente em Gramsci foi a necessidade de redimensionamento da luta revolucionária no sentido da construção de uma direção societária, de uma nova hegemonia. Ao analisar os processos desencadeados a partir da expansão capitalista e da derrota da luta proletária no início do século 20 , ele concluiu que, historicamente, os espaços de dominação presentes na sociedade, a exemplo do Estado, para se firmarem no bloco do poder, necessitam da permanente "desestruturação" das classes subalternas.

Neste sentido, Simionatto (2009) afirma que o Estado fortalece a subalternidade ao tomar como indistintas as diferenças existentes entre as classes fundamentais, bem como quando, no intuito de evitar ameaça à ordem existente, busca superar tais diferenças no âmbito das relações jurídicas. Na sociedade civil, a tarefa empreendida pela classe dominante direciona-se no sentido de reforçar o conformismo e de reduzir as classes subalternas aos interesses estritamente econômicos, corporativos.

Para Gramsci, uma das condições elementares para superação da subalternidade das classes e sua elevação à classe dirigente pressupõe, inicialmente, a própria superação do estágio econômico-corporativo. De acordo com Simionatto (2009, p. 43, grifos da autora), 
[...] nenhum grupo social possui condições de superar seus patamares de subalternidade até que não seja capaz de 'sair da fase econômico-corporativa para elevar-se à fase da hegemonia político-intelectual na sociedade civil e tornar-se dominante na sociedade política'.

Além disso, a "história episódica e fragmentada das classes subalternas" revela a dificuldade que estas têm de alcançar um nível de reflexão crítica sobre as relações de dominação às quais estão submetidas. Portanto, em Gramsci, a superação da subalternidade exige "a elaboração de uma concepção de mundo crítica e coerente, necessária para suplantar o senso comum e tornar as classes subalternas capazes de produzir uma contra-hegemonia" (SIMIONATTO, 2009, p. 43).

Para Gramsci (1999 apud SIMIONATTO, 2009), a superação da condição de subalternidade pressupõe, destarte, a construção de novos modos de pensar, uma nova concepção de mundo capaz de enfrentar, criticamente, o senso comum, uma vez que este não atravessa apenas a concepção de mundo das classes subalternas, porém a das demais classes e frações de classe, sob a forma de "ambiente cultural".

Vale ressaltar que todos(as), em alguma medida, contribuem para reprodução ou modificação do senso comum. A classe dominante o faz, porém, no sentido de desmobilizar "as iniciativas críticas advindas das classes subalternas" (SIMIONATTO, 2009, p. 43).

Gramsci (1968) observa que a construção de uma nova direção hegemônica pelas classes populares passa pela reformulação do senso comum, não no sentido de sua total eliminação, mas no sentido de elaboração de um novo senso comum, ou de um "bom senso", possível através da filosofia da práxis" ${ }^{12}$ ou seja, do próprio marxismo. Para tanto, conforme Acanda (2006), Gramsci enfatiza o papel fundamental do intelectual coletivo das classes subalternas, o partido político, na tarefa de empreender o processo de construção e difusão de uma nova concepção de mundo, crítica e totalizadora. Em outras palavras, para construir uma racionalidade nova, um projeto de elevação civil das camadas oprimidas da sociedade (DIAS, 1996a).

Apesar de ser uma tarefa que se inicia em nível ético-político e cognoscitivo, Gramsci $(1968$, p. 9) alerta que "uma reforma intelectual e moral não pode deixar de estar ligada a um programa de reforma econômica". Como sintetiza Dias (1996b, p. 42, grifos do autor), o partido político, quando se coloca como intelectual das classes subalternas precisa:

Colocar na ordem do dia a 'reforma econômica e modificação na posição social e no mundo econômico' [...] que são as formas e as possibilidades concretas de sua realização. Deve, a um só tempo, desconstruir 'todo o sistema de relações intelectuais e morais' [...], base sobre a qual se assenta a velha racionalidade e, ao mesmo tempo, 'inventar', construir o novo bloco histórico.

A superação do capitalismo não estaria circunscrita à tomada do Estado ${ }^{13}$ e às transformações econômicas, mas abrangeria a superação dos padrões civilizatórios particulares do modo de produção capitalista nas diferentes esferas: econômica, sociopolíticas, cultural e ideológica. Requer também a construção de uma nova direção hegemônica e de uma ordem societária capaz de superar a hegemonia burguesa.

\section{Considerações finais}

As elucubrações gramscianas, longe de se deterem ao campo da política, partem do ângulo da totalidade, colocando em relevo a indissociabilidade das esferas constitutivas da vida social.

Deste modo, ao evidenciar as raízes da (re)produção do sistema capitalista e a imprescindibilidade da hegemonia neste processo, suas reflexões iluminam a análise de fenômenos culturais e políticos que lhe eram contemporâneos, alertando para a necessidade de novas estratégias para superação do modo de produção capitalista.

Suas reflexões, porém, não estão restritas ao seu tempo histórico, mas continuam colocando elementos fundamentais para uma análise crítica das transformações das relações capitalistas em seu estágio atual. Contribuem para a análise do cenário contemporâneo, de crise estrutural do capitalismo, que tenta se reinventar em todas as esferas da vida social, através de processos que se estendem do campo estritamente produtivo (com a reestruturação produtiva), passando pela redefinição do papel do Estado (do neoliberalismo ao socialliberalismo, incluindo o novo desenvolvimentismo em curso na América Latina), bem como por todos os processos culturais e gnosiológicos em curso no cenário atual.

As reflexões de Gramsci colaboram também para a apreensão dos processos, muitas vezes subterrâneos, de construção de resistência ou de contestação que contribuem para a tessitura de uma nova hegemonia, de uma nova civilização. 


\section{Referências}

ACANDA, J. L. Sociedade civil e hegemonia. Tradução de Lisa Stuart. Rio de Janeiro: Ed. da UFRJ, 2006.

. Traducir a Gramsci. La Habana: Editorial de Ciencias Sociales, 2007.

. Gramsci. Recife, jan. 2010. [Notas de aula].

ANDERSON, P. Las antinomias de Antonio Gramsci: Estado y revolución em ocidente. Barcelona: Editorial Fontamara, 1981. BRAGA, R. Introdução. In: GRAMSCI, A. Americanismo e fordismo. Tradução de Gabriel Bogossian. São Paulo: Hedra, 2008, v. 1, p. 9-27. COUTINHO, C. N. Gramsci. Porto Alegre: L\&PM, 1981.

Marxismo e política: a dualidade de poderes e outros ensaios. São Paulo: Cortez, 1996.

. Notas sobre cidadania e modernidade. Revista Ágora: Políticas Públicas e Serviço Social, Ano 2, n. 3, 2005. Disponível em:<http://www.assistentesocial.com.br>. Acesso em: 5 mar. 2008.

De Rousseau a Gramsci: ensaios de teoria política. São Paulo: Boitempo, 2011.

DIAS, E. F. Sobre a leitura dos textos gramscianos: usos e abusos. In: DIAS, E. F. et al. (Org.). O outro Gramsci. São Paulo: Xamã, 1996a, p. 105-122.

Hegemonia: a racionalidade que se faz história. In: DIAS, E. F. et al. (Org.). O outro Gramsci. São Paulo: Xamã, 1996b, p. 9-79.

GRAMSCI, A. Maquiavel, a política e o Estado moderno. Tradução de Luiz Mário Gazzaneo. Rio de Janeiro: Civilização Brasileira, 1968. . Americanismo e fordismo. Tradução de Gabriel Bogossian. São Paulo: Hedra, 2008.

GRUPPI, L. Tudo começou com Maquiavel: as concepções de Estado em Marx, Engels, Lênin e Gramsci. Tradução de Dario Canali. Porto Alegre: L\&PM, 1980.

IAMAMOTO, M. V.; CARVALHO, R. Relações sociais e Serviço Social no Brasil: esboço de uma interpretação histórico-crítica. São Paulo: Cortez, 1985.

MARX, K. Fundamentos da História. In: IANNI, O. (Org.). Karl Marx: sociologia. Tradução de Maria Elisa Mascarenhas, Ione de Andrade e Fausto N. Pellegrini. São Paulo: Ática, 1979, p. 45-61.

. A questão judaica. Tradução de Silvio Donizete Chagas. São Paulo: Martin Claret, 2005.

Crítica ao Programa de Gotha. Rocket Edition, 1999. Versão para e-book. Disponível em: <http://www.ebooksbrasil.org/ eLibris/gotha.html>. Acesso em: 27 set. 2010.

MARX, K.; ENGELS, F. Manifesto do partido comunista. Prefácio de José Paulo Netto. Tradução de Rubens Enderle, Nélio Schnneider e Luciano Martorano. São Paulo: Cortez, 1998.

NEVES, L. M. W. (Org.). A nova pedagogia da hegemonia: estratégias do capital para educar o consenso. São Paulo: Xamã, 2005. PORTELLI, H. Gramsci e o bloco histórico. Tradução de Angelina Peralva. Rio de Janeiro: Paz e Terra, 2002.

SIMIONATTO, I. Gramsci: sua teoria, incidência no Brasil, influência no Serviço Social. Florianópolis: Ed. da UFSC; São Paulo: Cortez, 2004. . Classes subalternas, lutas de classe e hegemonia: uma abordagem gramsciana. Revista Katálysis, Florianópolis: Edufsc, v. 12, n.1, p. 41-49, 2009. Disponível em: <www.scielo.br/pdf/rk/v12n1/06.pdf>. Acesso em: 20 out. 2011.

O social e o político no pensamento de Gramsci. In: AGGIO, A. (Org.). Gramsci: vitalidade de um pensamento. São Paulo: Ed. da Unesp, 1998, p. 37-64.

\section{Notas}

1 Anderson (1981) reconhece as contribuições do italiano para a teoria marxista sobre o Estado e a política, mas expõe o que considera serem as “antinomias" do pensamento gramsciano. Sobre esta obra, Acanda (2010) alerta que o objetivo de Gramsci era enfrentar o reformismo dos comunistas anglo-saxões que o usavam para justificar suas posições. Acanda observa ainda que, no momento em que Anderson (1981) escreveu, a obra gramsciana ainda não havia sido completamente traduzida, o que explicaria uma parcela dos elementos contraditórios que aquele autor encontra nos Cadernos do cárcere.

2 Conforme sinaliza Coutinho (1981), até o cárcere, a obra de Gramsci era de caráter circunstancial, composta por artigos jornalísticos, informes políticos, discursos etc. Nos Cadernos, Gramsci buscava um trabalho mais sistemático, porém seus problemas de saúde e as condições da reclusão o impossibilitaram de alcançar seu objetivo. Isso resultou, como mostra Acanda (2006), em um texto fragmentado e por vezes inconcluso, no qual o autor vai de uma temática a outra. Vale destacar também que os textos gramscianos dos tempos da prisão passavam pela censura dos carcereiros, o que fez com que ele tivesse que usar, em diversos momentos, uma linguagem cifrada. Outro problema elencado em relação aos Cadernos diz respeito às condições de sua publicação, seja porque eram submetidas a censuras, não apenas dos carcereiros, porém, inclusive, de parte dos marxistas ligados à III Internacional Comunista; seja porque foram publicados inicialmente de maneira temática, fraturando ainda mais o pensamento do autor. Apesar desse perfil literário de certa forma fragmentado, as obras de Gramsci realizam reflexões que, tendo como solo a realidade histórica e política da Itália e da Europa da época, projetam-se para um âmbito mais amplo, "tornando-a capaz de responder e de incidir sobre uma práxis mais vasta, mais universal" (COUTINHO, 1981, p. 64).

3 O pensamento de Gramsci, com o uso das devidas mediações, traz elementos fundamentais para analisar a crise societária atual (abordagem que se pode verificar em Neves, 2005, por exemplo), o que não será, porém, objetivo da reflexão do atual texto.

4 Marx não possui obra que discuta especificamente a questão do Estado, portanto esta só pode ser entendida no conjunto de sua análise sobre a 
sociedade capitalista.

5 Gramsci (1968) coloca a necessidade de análises cuidadosas da relação entre estrutura e superestrutura, no sentido de apreender as forças atuantes na história. Há que atentar para os supostos marxianos de que nenhuma sociedade se coloca encargos que não pode resolver e que nenhuma sociedade desaparece antes que se desenvolvam todas as formas de vida possíveis em suas relações. No estudo da estrutura, de acordo com Gramsci, há que se diferenciar os movimentos orgânicos (relativamente permanentes) dos movimentos de conjuntura (que se evidenciam como ocasionais, imediatos).

6 Aqui nos referimos ao que Gramsci (1968, p. 159) denomina de grande política, relacionada "à fundação de novos Estados, com a luta pela destruição, a defesa, a conservação de determinadas estruturas orgânicas econômico-sociais", distinta da pequena política, que "compreende as questões parciais e quotidianas que se apresentam no interior de uma estrutura já estabelecida, em virtude das lutas pela predominância entre as diversas frações de uma mesma classe política".

7 Esse novo equilíbrio psicofísico deve ser vivido como interioridade, "interioridade que significa, em última instância, a absorção subjetiva dessa objetivação social, a introjeção da hegemonia: o atuar segundos normas conformes a esse ambiente produtivo, essa interioridade é o índice da hegemonia em processo. O american way of life mais do que instrumento de propaganda, é a forma que assume esse novo modo de ser, necessário ao novo ambiente produtivo" (DIAS, 1996b, p. 69).

8 Segundo Acanda (2007, p. 125), o fetichismo não é um conceito econômico, mas gnosiológico, e consiste no "ocultamiento del carácter de las relaciones sociales. La fetichización de los fenómenos sociales es resultado del carácter enajenado y enajenante de la producción en las condiciones del capitalismo".

9 Acanda (2006, p. 201) indica que o próprio conhecimento deve ser analisado a partir da política e não somente da filosofia, posto que "as relações de poder funcionam como elemento condicionador do processo de produção e difusão das formas de saber, dos códigos de representação, dos processos de apropriação espiritual da realidade".

10 Dias (1996b) alerta que a hegemonia não se move apenas no terreno da racionalidade, mas também no campo da afetividade.

11 Em Gramsci, apenas metodologicamente é possível estabelecer uma distinção entre sociedade política e sociedade civil, posto que tais dimensões doEstado se idealizam em articulação dialética e indissociável.

12 Segundo Gramsci (1968, p. 44),“a filosofia da práxis não objetiva 'manter os simples na sua filosofia primitiva de senso comum, mas pretende, ao contrário, conduzi-los a uma concepção de vida superior', buscando forjar um bloco intelectual-moral que torne politicamente possível um progresso intelectual de massa e não apenas de pequenos grupos intelectuais".

13 De maneira distinta de boa parte dos marxistas de sua época, Gramsci (1968, p. 74-75) afirma que a revolução, no Ocidente, não poderia ser pensada somente como um assalto ao aparelho de poder político-coercitivo. Isso porque, "no Oriente, o Estado era tudo, a sociedade civil primordial e gelatinosa; no Ocidente, havia entre o Estado e a sociedade civil uma justa relação e em qualquer abalo do Estado imediatamente descobria-se uma poderosa estrutura da sociedade civil. O Estado era apenas uma trincheira avançada, por trás da qual se situava uma robusta cadeia de fortalezas e casamatas; em medida diversa de Estado para o Estado, é claro, mas exatamente isto exigia um acurado reconhecimento do caráter nacional."

\section{Kathleen Elane Leal Vasconcelos}

leal.kathleen@gmail.com

Doutoranda em Serviço Social na Universidade Federal de Pernambuco (UFPE)

Professora da Universidade Estadual da Paraíba (UEPB), Campina Grande, Paraíba

\section{Mauricelia Cordeira da Silva}

mauriceliacordeiro@ hotmail.com

Mestre em Serviço Social pelo Programa de Pós-Graduação em Serviço Social da UFPE

Professora no Curso de Serviço Social da Faculdade Leão Sampaio, Juazeiro do Norte, Ceará

\section{Valdilene Pereira Viana Schmaller}

valdileneviana@uol.com.br

Doutora em Serviço Social pela UFPE

Professora do Departamento de Serviço Social e do Programa de Pós-Graduação em Serviço Social da UFPE

\section{UFPE - Departamento de Serviço Social}

Centro de Ciências Sociais Aplicadas, $1^{\circ}$ andar

Rua Prof. Moraes Rego, 1235

Recife - Pernambuco - Brasil

CEP: 50670-901 